\title{
An Examination of Undergraduate Student's Perceptions and Predilections of the Use of YouTube in the Teaching and Learning Process
}

\author{
Nicole A. Buzzetto-More \\ University of Maryland Eastern Shore, MD, USA
}

\section{nabuzzetto-more@umes.edu}

\begin{abstract}
Pervasive social networking and media sharing technologies have augmented perceptual understanding and information gathering and, while text-based resources have remained the standard for centuries, they do not appeal to the hyper-stimulated visual learners of today. In particular, the research suggests that targeted YouTube videos enhance student engagement, depth of understanding, and overall satisfaction in higher education courses.

In order to investigate student perceptions and preferences regarding the implications of YouTube, a study was conducted at a Mid-Atlantic minority serving institution that examined student opinions regarding the usage of YouTube videos to augment instruction in online and classroombased courses. According to the findings, use of YouTube in the teaching and learning process enhances instruction with students most likely to visit video sharing services from mobile devices. Further, length has an impact on student decisions whether or not to watch a video, and course delivery format impacts length and audio preferences. Finally, there is no relationship between personal use of social media and the perceived value of the use of YouTube in the instructional process.
\end{abstract}

Keywords: YouTube in Education, Instructional Video, Video Sharing Services, Social Media, User Generated Content, Student Engagement and YouTube, YouTube in Teaching and Learning, Video-Based Learning, Social Learning, Mobile Learning, mLearning, Web-based Video, Educational Video Production, Audio Preferences of Students, Video Length

\section{Introduction}

Social networking systems come in many forms from bookmarking services like Delicious, Pinterest, and BibSonomy; to 3D Virtual Worlds like Second life; professional networking systems like LinkedIn; Blogging tools like Blogger; microblogging tools like Twitter; collaborative con-

Material published as part of this publication, either on-line or in print, is copyrighted by the Informing Science Institute. Permission to make digital or paper copy of part or all of these works for personal or classroom use is granted without fee provided that the copies are not made or distributed for profit or commercial advantage AND that copies 1) bear this notice in full and 2) give the full citation on the first page. It is permissible to abstract these works so long as credit is given. To copy in all other cases or to republish or to post on a server or to redistribute to lists requires specific permission and payment of a fee. Contact Publisher@InformingScience.org to request redistribution permission. tent creation tools such as Wikipedia or Wikispaces; photo sharing services like Flickr and Instagram; profile and friend management/communications systems like Facebook and MySpace; video sharing services like YouTube; and microvideo blogging services like Vine. Inherent to all is the concept of user generated content, sharing, and social commentary, which have been found to encourage student expression and partici- 
pation as well as foster social learning theory (Buzzetto-More, 2012a). Further, they have all been found particularly effective at appealing to digital natives (Buzzetto-More, 2012b; BuzzettoMore, 2013a).

This paper specifically explores Web-based video services. Accordingly, two types of video services available online were identified as (1) video viewing services that allow users to view videos, and (2) video sharing services that allow individuals to upload videos and share them with others for commentary.

A February 2014 article by eMBA (2014) presented the top 15 video viewing and sharing services, by reporting such information as number of unique monthly visitors and Alexa, Quantcast, and eMBA rankings. Table 1 presents the findings, which demonstrate the dominance of YouTube with an estimated 1 billion unique monthly visitors compared to the 150 million visitors of the second most popular video viewing Website Netflix. Additionally, the chart designates whether a services includes video sharing capabilities.

\begin{tabular}{|c|c|c|c|c|c|}
\hline \multicolumn{6}{|c|}{$\begin{array}{l}\text { Table } 1 \\
\text { eMBA Report February } 2014 \text { Top } 15 \text { Video Viewing Sites by Visitors }\end{array}$} \\
\hline NAME & $\begin{array}{c}\text { UNIQUE } \\
\text { MONTHLY } \\
\text { VISITORS }\end{array}$ & $\begin{array}{l}\text { ALEXA } \\
\text { RANK }\end{array}$ & $\begin{array}{l}\text { QUANTCAST } \\
\text { RANK }\end{array}$ & $\begin{array}{l}\text { eMBA } \\
\text { Rank }\end{array}$ & $\begin{array}{l}\text { Video Shar- } \\
\text { ing }\end{array}$ \\
\hline YOUTUBE & $1,000,000,000$ & 3 & 2 & 3 & $\mathrm{Y}$ \\
\hline NETFLIX & $150,000,000$ & 97 & 192 & 106 & $\mathrm{~N}$ \\
\hline YAHOO SCREEN & $125,000,000$ & NA & 110 & 108 & $\mathrm{Y}$ \\
\hline VIMEO & $120,000,000$ & 100 & 56 & 110 & $\mathrm{Y}$ \\
\hline DAILY MOTION & $100,000,000$ & 95 & NA & 128 & $\mathrm{Y}$ \\
\hline HULU & $75,000,000$ & 313 & 115 & 183 & $\mathrm{~N}$ \\
\hline VUBE & $55,000,000$ & NA & 678 & 272 & $\mathrm{Y}$ \\
\hline LIVE LEAK & $40,000,000$ & 470 & 95 & 381 & $\mathrm{Y}$ \\
\hline TWITCH & $35,000,000$ & 313 & 331 & 523 & $\mathrm{Y}$ \\
\hline BREAK & $20,000,000$ & 1413 & NA & 707 & $\mathrm{Y}$ \\
\hline METACAFE & $18,500,000$ & 1124 & 340 & 740 & $\mathrm{Y}$ \\
\hline USTREAM & $16,000,000$ & 1103 & NA & 754 & $\mathrm{Y}$ \\
\hline TV.COM & $14,000,000$ & 1854 & 662 & 894 & $\mathrm{~N}$ \\
\hline VIEWSTER & $12,000,000$ & 2844 & 562 & 1175 & $\mathrm{~N}$ \\
\hline CRACKLE & $10,000,000$ & 4388 & 1156 & 1863 & $\mathrm{~N}$ \\
\hline
\end{tabular}

When only video sharing services are considered there are currently over 50 such services available (Preece, 2014). These services vary considerably and were ranked by Preece (2014) who considered five categories:

- audience features such as search-ability; 
- screenshot previews; incorporation of user ratings and descriptions;

- producer features that assist in video uploading and creation; overall content;

- ease of use; and help and support.

Based on the criteria considered and analyses performed, YouTube was the only video sharing service that scored a perfect 50 (Preece, 2014), with the complete top 10 depicted in Figure 1.

Figure 1: Top 10 Video Viewing Websites According to Preece (2014)

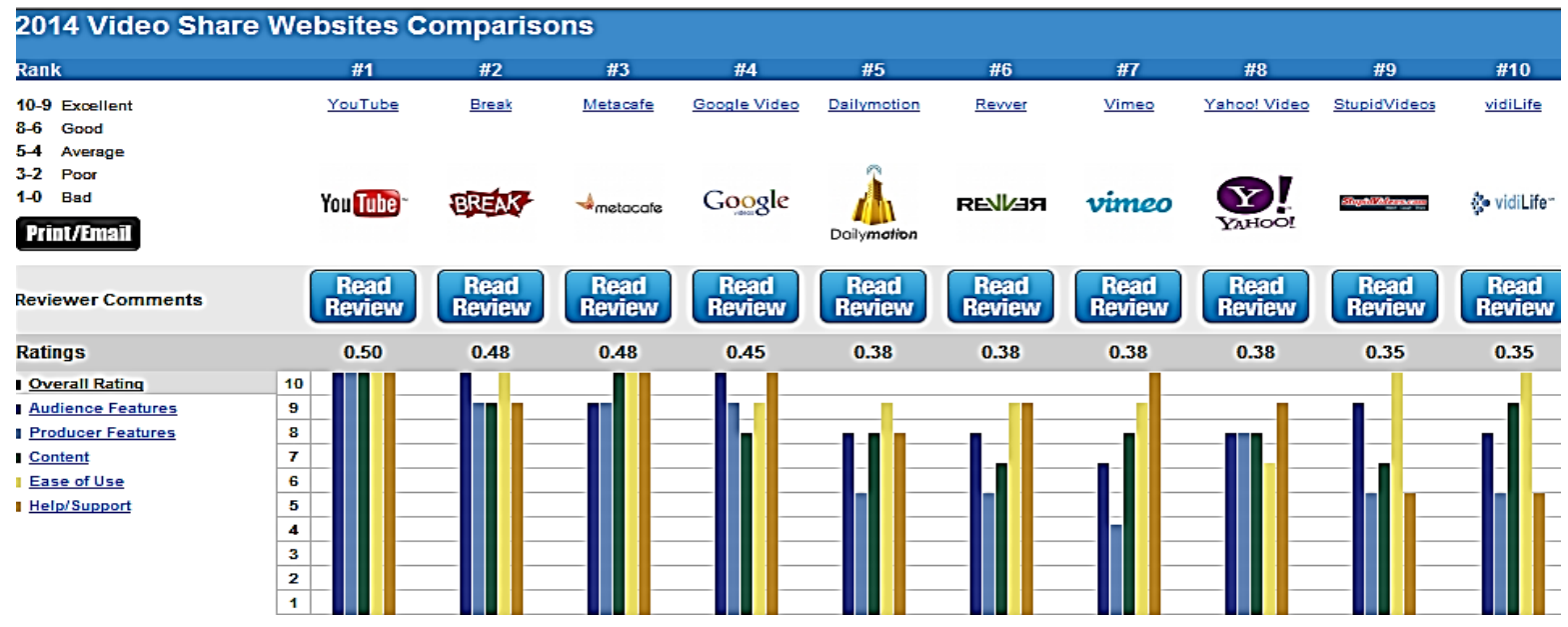

YouTube, which is a subsidiary of Google Inc., is the Goliath of video sharing services. YouTube supports the distribution, sharing, and organization of user-generated video. The service allows unregistered users to watch videos and post comments and allows registered users to upload movie clips, television clips, music videos, original short videos, documentaries, animated shorts, slideshows, as well as video captured via mobile devices.

YouTube allows users to create custom YouTube channels as well as embed videos on other social networking pages and blogs using HTML code. It also allows users to share, send, and leave comments about videos.

A vast range of videos are available for viewing. In terms of the most popular types of videos viewed by category music has consistently been found to be the most popular, followed by entertainment, and people/blogs (Sysomos, 2009).

Approximately, 60 hours of video are uploaded to the YouTube Server every minute, or one hour of video is uploaded to YouTube every second; over 4 billion videos are viewed each day, and over 3 billion hours of video are watched each month (Prigg, 2012). The average user spends 20 minutes per day on the site and more video is added to YouTube per month than the 3 major US TV networks created in 60 years (Prigg, 2012). On Facebook alone 500 years of YouTube videos are watched each day and over 700 YouTube videos are shared on Twitter each minute. Finally, YouTube is currently the number 2 search engine on the Web (Buzzetto-More, 2013b).

YouTube provides free access to a huge volume of educational videos. YouTube EDU is a service for educators which contains short lessons from teachers, full university courses, professional development materials, and inspirational videos from global leaders. YouTube Teachers was created to help K-12 teachers use educational videos to educate, engage, and inspire students with content aligned to Common Core Standards. Finally, YouTube for Schools is an opt-in program that allows schools to access thousands of educational videos from vetted YouTube channels like PBS, TED, and Khan in a secure environment. 
This paper reports the results of a study conducted in the spring of 2013 at a Mid-Atlantic minority serving institution that sought to examine student perceptions regarding the usage of YouTube videos to augment instruction in online and classroom-based courses. YouTube was specifically selected because of students' existing familiarity and wide-spread usage of the system. We were interested in discovering how students are most likely to visit YouTube because the device and system used may have implications in terms of delivery, accessibility, and methods of infusion. Differences in perceptions based on course delivery method were also explored in order to determine whether perceptual differences exist between online and classroom-based learners. Additionally, student preferences with respect to auditory and length design considerations were explored in order to better inform the video production and/or selection processes.

A course delivered in fully online, and hybrid formats was modified in order to incorporate the heavy usage of YouTube videos throughout the instructional process. The instructor designed a number of the videos utilized. Course lecture notes were made available in MS PowerPoint, MS Word, as well as in YouTube video formats. Additional videos were created to enhance student understanding of key course concepts as well as to introduce concepts in a more dynamic format. A variety of YouTube videos that were not created by the instructor were also incorporated. These videos ranged from documentary segments, relevant excerpts from television shows, scenes from mainstream movies, interviews, lectures from professors at other Universities, short presentations, and thought provoking and/or amusing videos relevant to course content. YouTube videos were also incorporated into two online discussions (one where students watched and analyzed several videos from a list of available videos and another where students located and shared videos with their classmates), two course assignments, and an extra credit opportunity. Other features of the courses included use of a separate online adaptive response assessment system linked to the course e-text, an online grade book, and involvement of a Web-based simulation. The Blackboard LMS was utilized as the primary delivery instrument, which enables the embedding of videos directly from YouTube. The hybrid version of the course operated much in the same as the online class with the exception that it included weekly meetings and thusly less emphasis on online discussions and interactions. Following completion of the courses, a survey was administered using the online survey tool Zoomerang.

\section{Literature Review}

Social media have been found to foster social learning serving as effective tools to supplement more traditional modes of instruction (Buzzetto-More, 2012c). More specifically, the literature suggests that well-selected YouTube videos help students engage more deeply with subject matter and recall the information they've learned longer (Burke \& Snyder, 2008; Hilner, 2012). Additionally, YouTube videos have been shown to increase students' depth of understanding of course content (Buzzetto-More, 2013a; Cardine, 2008; Hilner, 2012; Jones \& Graham, 2013; Logan, 2012; Tan \& Pearce, 2012). Use of YouTube has also been specifically shown to enhance online courses (Jones \& Graham, 2013). In particular, YouTube has been found to facilitate course discussions, enhance lectures, encourage independent learning, and assist in tutoring in online courses (Berk, 2009; Logan, 2012; Miller, 2009).

A study sponsored by Cisco Systems (Greenberg \& Zanetis, 2012) found online videos to be an educational "enabler and complimentary tool" in the teaching and learning process (p. 3) that stimulates greater interactivity with content, increased engagement, more rigorous discourse, and enhanced knowledge transfer, and memory building the result of which is increased neural development and academic performance. Further, the study concluded that shorter video segments had greater appeal than longer segments recommending that videos refrain from exceeding 15 minutes in length. In conclusion, they explained that students today are visual spatial learners who are 
motivated by, and able to multi-task with, multi-media thus inspired and motivated by online video usage (Greenberg \& Zanetis, 2012).

Examining the impact on learning, Berk (2009) concluded that the verbal and visual components of a video provide a best fit to the characteristics of the Net Generation of students and a valid approach to tap their multiple intelligences and learning styles. Berk's assertions are similar to the findings of Miller (2009) who examined the incorporation of multimedia content in a sociology course concluding that educational videos help students to conceptualize key ideas so as to enhance understanding.

A UK case study of the use of YouTube videos in learning and teaching in an introductory sociology course for mature and international students (Tan, \& Pearce, 2012) found that the use of YouTube was an effective way of supporting learning. Using case studies and student artifacts, the authors surmised that YouTube helps students learn by providing alternative views and opinions on subjects, variety in delivery mechanisms, and the use of every day examples to illustrate points.

Focusing on an integrated science course for nonscience majors using embedded content-related video segments from YouTube, Eick and King (2012) examined students' perceptions of how video use engaged them and increased their interest and understanding. Following analysis of survey responses they concluded that the videos helped to keep students' attention, generated interest in science, supported conceptualization through visualization, provided students with memory cues and connections, and clarified understanding.

In a study that examined the perceptions of second year medical students in a human anatomy course supported by a YouTube channel, the author (Jaffar, 2012) found that $98 \%$ of the students used YouTube as an online information resource, albeit in different frequencies. Out of the students who had visited the course YouTube channel, 92\% agreed/strongly agreed that the channel helped them better learn anatomy. The author also concluded that YouTube can be considered as an effective tool to enhance instruction and support independent learning in a PBL classroom if the videos are scrutinized, diversified, and aimed toward course objectives (Jaffar, 2012).

In a study conducted at the University of Houston, Liu (2010) found that YouTube videos provide students with increased choices and control over the direction of learning so as to engender greater personalization of the learning experiences. These findings are similar to what was reported by Logan (2012) who examined use of YouTube in nursing education and concluded that YouTube videos can be used as a component of an active learning strategy that can appeal to a broad group of students' along the novice-to-expert proficiency continuum.

Noel-Levitz, OmniUpdate, CollegeWeekLive, and NRCCUA conducted a study of mobile social media use, surveying nearly 2,300 college-bound high school students finding that $84 \%$ of college bound high school seniors use Facebook, 78\% use YouTube, and 25\% use Twitter. Further, they study found that when it comes to Facebook and YouTube, a large proportion of high school students now access these sites via mobile devices (Noel-Levitz, 2012).

\section{Methodology}

This paper reports the findings of a study conducted in the spring of 2013 at a Mid-Atlantic minority serving institution that sought to examine student perceptions regarding the usage of YouTube videos to augment instruction in online and hybrid courses. In order to examine student perceptions a survey was developed and delivered using the Zoomerang/Survey Monkey system. Pre-testing was done in order to inform the survey design process. The developed survey was comprised of a combination of dichotomous, Likert-scaled, ordinal, ratio, short answer, Guttmann scaled, and contingency questions. The survey was evaluated by several content and methodo- 
logical experts in order to examine bias, vagueness, or potential semantic problems. Finally, the survey was pilot tested prior to implementation in order to test the efficacy of the research methodology and modified accordingly. The finalized survey was completed by 221 respondents, representing a response rate greater than $60 \%$.

During the data analysis process descriptive statistics and frequency distribution were examined. Additionally, cross tabulations were performed and contingency tables produced. Finally, a limited number of Anova's were performed in order to compare means.

During the analysis process, the following hypotheses were tested:

Hypothesis $1\left(\mathrm{H}_{1}\right)$ : Use of YouTube enhances instruction.

Hypothesis $2\left(\mathrm{H}_{2}\right)$ : Students are most likely to visit YouTube from a mobile device

Hypothesis $3\left(\mathrm{H}_{3}\right)$ : Frequent users of social networking services like Facebook and YouTube are more likely to accept use of YouTube in the teaching and learning process

Hypothesis $4\left(\mathrm{H}_{4}\right)$ : Length has an impact on the decision to view a video

Hypothesis $5\left(\mathrm{H}_{5}\right)$ : Course delivery format impacts length preferences

Hypothesis $6\left(\mathrm{H}_{6}\right)$ : Course delivery format impacts audio preferences

\section{Findings}

Forty-five percent of respondents were male and 55\% female. In terms of race and ethnicity, the majority of respondents (61.2\%) identified themselves as African American, 18.7\% selfidentified as white or of European Descent, 6.4\% reported that they are African, 3.2\% said that they are Hispanic, 3.2\% categorized themselves as Asian/Pacific Islander, 2.3\% self-identified as a Caribbean Islander, .5\% reported being Middle Eastern, and 4.5\% self-identified as other. When age was asked $79.4 \%$ of respondents reported being between 18 and $24,15.6 \%$ said that they were $25-31,1.8 \%$ reported that they were $32-40$, and $3.2 \%$ of respondents reported being over 41 . Table 2 depicts the demographic distribution of respondents.

\begin{tabular}{|lc|}
\hline \multicolumn{1}{|c|}{ Table 2: Demographic Distribution } \\
\hline Race & Response Percent \\
African American & $61.2 \%$ \\
African & $6.4 \%$ \\
Hispanic & $3.2 \%$ \\
Middle Eastern & $0.5 \%$ \\
Caribbean Islander & $2.3 \%$ \\
Asian/Pacific Islander & $3.2 \%$ \\
White or European Descent & $18.7 \%$ \\
Other & $4.5 \%$ \\
Age & \\
$18-24$ & $79.4 \%$ \\
$25-31$ & $15.6 \%$ \\
$32-40$ & $1.8 \%$ \\
$>41$ & $3.2 \%$ \\
\hline
\end{tabular}

Prior exposure to YouTube was ascertained. According to the findings, $98 \%$ of respondents had used YouTube previously; however, only $26.5 \%$ had ever posted to a video sharing service. 
These results are displayed in Table 3 and are consistent with what has been reported by Jaffar (2012) and Noel-Levitz, (2012), which found similar rates of YouTube usage.

Table 3: Responses to Dichotomous Questions

\begin{tabular}{|l|c|c|}
\hline Answer Options & Yes & No \\
\hline Used YouTube Prior to This Course & $98 \%$ & $2 \%$ \\
\hline $\begin{array}{l}\text { Have Posted a Video to a Video Sharing Service Like } \\
\text { YouTube }\end{array}$ & $26.5 \%$ & $83.5 \%$ \\
\hline
\end{tabular}

Respondents were asked to consider their use of a number of Web 2.0 tools and rank their use on a scale of 1-5 where 1 equaled never tried, 2 equaled tried a couple of times, 3 equaled use occasionally, 4 equaled use weekly, and 5 equaled use daily. According the responses, average use of Facebook was the highest $\mu 4.00$ with a standard deviation of 1.122 and a confidence interval @ $95 \%$ of 0.05 . YouTube was second $\mu 3.80$ with a standard deviation of 0.904 and a confidence interval @ 95\% of 0.041. This data is presented in Table 4 and is consistent with what has been reported in the literature (Noel-Levitz, 2012). Additionally, all means for tools examined are represented in Figure 2.

\begin{tabular}{|l|l|l|}
\hline \multicolumn{3}{|c|}{ Table 4: Frequency of Use of Facebook and YouTube } \\
\hline & FACEBOOK & YOUTUBE \\
\hline Mean & 4.00 & 3.80 \\
\hline Skew & -0.78974 & -0.29343 \\
\hline Standard Deviation & 1.12208 & 0.90412 \\
\hline Confidence @ 95\% & 0.05091 & 0.041021 \\
\hline
\end{tabular}

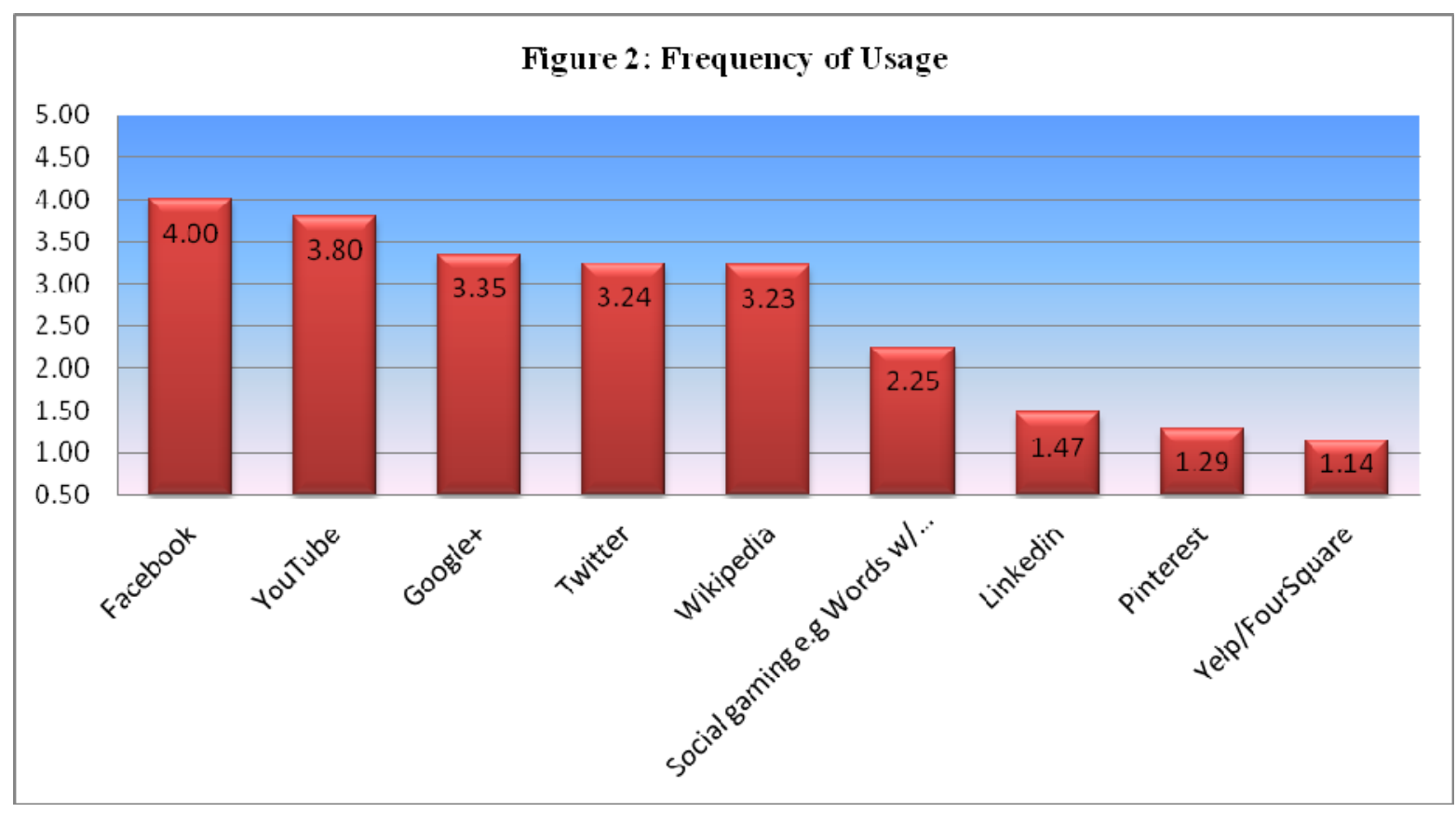


Using a contingency approach, individuals who responded that they had prior experience using YouTube were asked to select all of the types of videos that they watch on YouTube. According to the respondents, music videos, funny videos, how-to videos, news/documentary videos, and informational videos were the most common. The responses to this question are represented in Table 5 and are consistent with, although a more detailed examination than, what was reported by a study conducted by Sysomos (2009).

\begin{tabular}{|lc|}
\hline \multicolumn{2}{|c|}{ Table 5: Types of Videos Watched on YouTube } \\
\hline Type of Video & Response Percent \\
\hline Music Videos & $91.4 \%$ \\
\hline Funny/Viral Videos/People Caught on Tape & $75.5 \%$ \\
\hline How to Videos & $61.4 \%$ \\
\hline News/Documentary Videos & $57.3 \%$ \\
\hline Informational Videos & $43.2 \%$ \\
\hline Celebrity Videos & $39.1 \%$ \\
\hline Videos Posted by My Friends & $39.1 \%$ \\
\hline Viral Videos other & $38.6 \%$ \\
\hline Free Movies & $35.5 \%$ \\
\hline Social Commentaries & $23.6 \%$ \\
\hline Animations or Cartoons & $18.2 \%$ \\
\hline Gaming Play Through Videos/ Walkthroughs & $11.4 \%$ \\
\hline
\end{tabular}

Respondents were asked "In a typical week, how likely are you to use video viewing websites?" According to the respondents $53.9 \%$ were either extremely likely or very likely to visit a video viewing site, $36.5 \%$ said that they were moderately likely, $6.3 \%$ were slightly likely, and $3.2 \%$ were not at all likely. The results are depicted in Figure 3 and show more modest usage than what has been commonly reported in the literature (Prigg, 2012). 


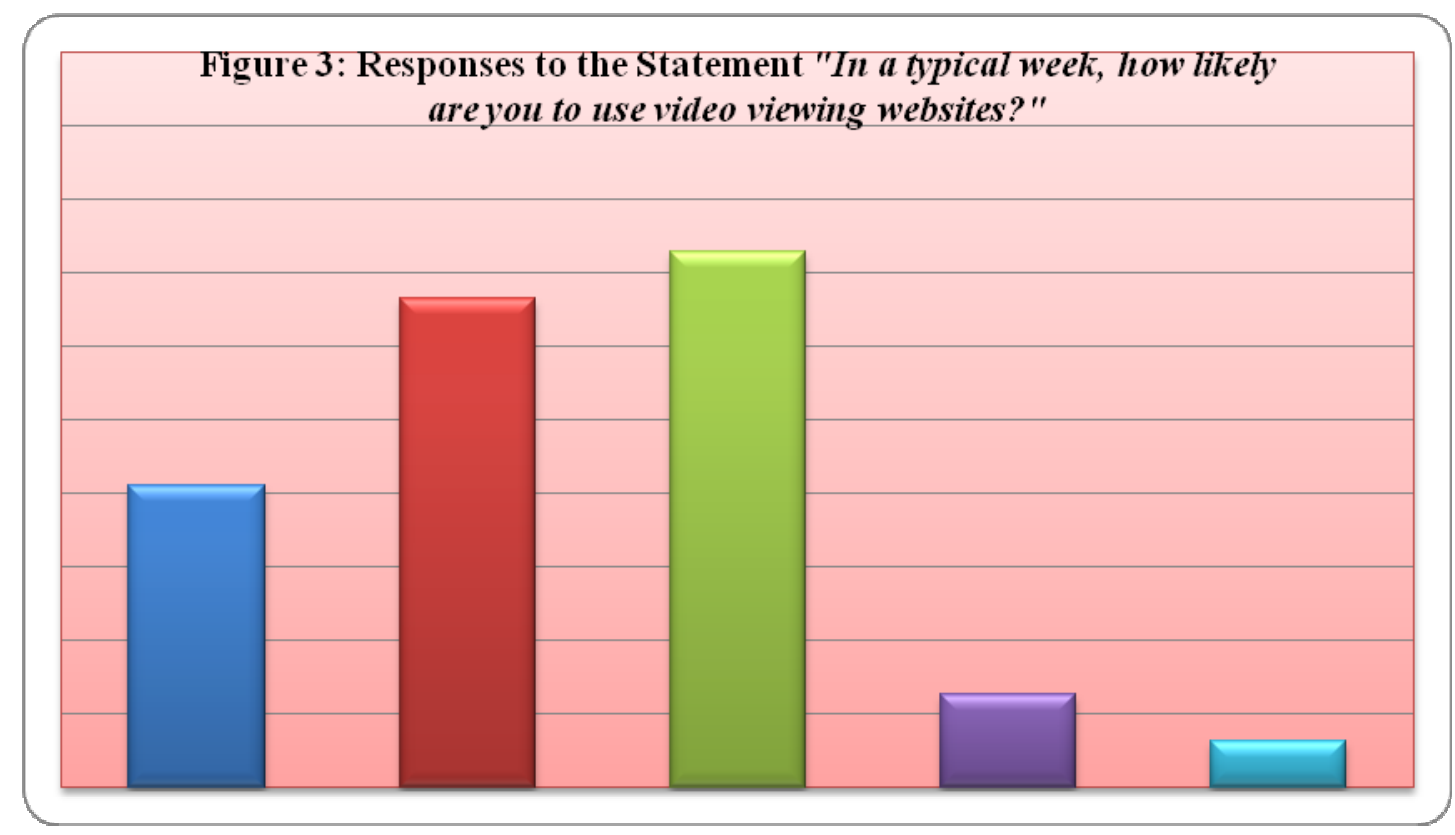

In order to enable comparative analyses and support hypotheses testing, participants were asked to indicate their preferred course delivery format; whereas $26 \%$ of respondents indicated a preference for fully online courses, $54 \%$ indicated a preference for hybrid courses, and $20 \%$ indicated a preference for fully synchronous classroom-based courses.

\section{Discussion}

The following discussion focuses on the investigation and testing of the following hypotheses:

Hypothesis $1\left(\mathrm{H}_{1}\right)$ : Use of YouTube enhances instruction.

Hypothesis $2\left(\mathrm{H}_{2}\right)$ : Students are most likely to visit YouTube from a mobile device

Hypothesis $3\left(\mathrm{H}_{3}\right)$ : Frequent users of social networking services like Facebook and YouTube are more likely to accept use of YouTube in the teaching and learning process

Hypothesis $4\left(\mathrm{H}_{4}\right)$ : Length has an impact on the decision to view a video

Hypothesis $5\left(\mathrm{H}_{5}\right)$ : Course delivery format impacts length preferences

Hypothesis $6\left(\mathrm{H}_{6}\right)$ : Course delivery format impacts audio preferences

\section{Hypothesis $1\left(\mathrm{H}_{1}\right)$ : Use of YouTube enhances instruction}

In order to test Hypothesis $1\left(\mathrm{H}_{1}\right)$ : "Use of YouTube enhances instruction" respondents were asked to respond to two Likert-scaled agreement questions where 1 equaled strongly disagree, 2 equaled disagree, 3 equaled neutral or undecided, 4 equaled agree, and 5 equaled strongly agree. According to the respondents $70.7 \%$ agreed/strongly agreed that "the use of YouTube can enhance the learning process" $\mu 3.85$ and $89 \%$ agreed/strongly agreed that "the use of YouTube as a learning tool engages students" $\mu 4.19$. These findings, which are represented in Table 6 , support Hypothesis 1 and are consistent with what has been reported in the literature (Buzzetto-More, 2013a; Duvenger \& Steffes, 2012; Eick \& King, 2012; Greenberg \& Zanetis, 2012; Hilner, 2012; Jaffar, 2012; Jones \& Graham, 2013; Pratt \& Feikes, 2013; Tan \& Pearce, 2012). 


\begin{tabular}{|l|l|l|}
\hline \multicolumn{3}{|c|}{ Table 6: Student Perceptions of YouTube in Course Instruction } \\
\hline & $\begin{array}{l}\text { The Use of YouTube can en- } \\
\text { hance the learning process }\end{array}$ & $\begin{array}{l}\text { The use of YouTube as a learning } \\
\text { tool engages students }\end{array}$ \\
\hline Mean & $\mathbf{3 . 8 5 7}$ & $\mathbf{4 . 1 9 7 2}$ \\
\hline Skew & -0.798504 & -1.075795 \\
\hline Standard Deviation & 0.907195 & 0.7136533 \\
\hline Confidence @ 95\% & 0.041160 & 0.0323792 \\
\hline
\end{tabular}

Cross tabulations were also performed to examine the differences in the responses based on preferred course delivery format. While all students agreed that "use of YouTube can make classes more interesting", those students who indicated a preference for fully online courses were more positive in their opinions regarding the educational benefits of YouTube. Table 7 presents the results of the cross tabulation, which is consistent with what has been reported in the literature (Jones \& Graham, 2013; Pratt \& Feikes, 2013).

\begin{tabular}{|l|c|c|c|c|c|c|}
\hline \multicolumn{7}{|l|}{ The use of YouTube can enhance the learning process. } \\
\hline & \multicolumn{7}{|c|}{ What type of course format do you prefer? } \\
\hline Answer Options & $\begin{array}{c}\text { Fully } \\
\text { Online }\end{array}$ & Hybrid & $\begin{array}{c}\text { In- } \\
\text { Person }\end{array}$ & \multicolumn{2}{|c|}{ Total } & Mean \\
\hline & 0 & 4 & 1 & 5 & \\
Strongly Disagree & 0 & 7 & 2 & 9 & \\
\hline Disagree & 10 & 26 & 14 & 50 & \\
\hline Neutral/Undecided & 27 & 52 & 21 & 100 & \\
\hline Agree & 17 & 30 & 4 & 51 & \\
\hline Strongly Agree & 54 & 119 & 42 & 215 & \\
\hline Total & 4.13 & 3.82 & 3.60 & 215 & \\
\hline Mean & & & & & \\
\hline
\end{tabular}

\section{Hypothesis $2\left(\mathrm{H}_{2}\right)$ : Students are most likely to visit YouTube from a mobile device}

YouTube uses the built-in multimedia capabilities of web browsers supporting the HTML5 standard, accessible via most devices (computers, laptops, smartphones, tablet computers, portable multimedia players like the iPod touch, and most contemporary ebook readers). Unlike Flash files, video viewing is not dependent on the use of specific proprietary software. Additionally, because videos are hosted on, and play from, the YouTube server, a file download is not required to watch a video. Finally, display of YouTube videos remains consistent regardless of device, something that is an issue with many file types, such as PowerPoint, commonly used in education.

Respondents were asked how they are most likely to access YouTube. Most respondents (57.5\%) reported that they access YouTube using a phone or other mobile device, followed by $40.6 \%$ who 
reported using a laptop or personal computer, and $1.8 \%$ who cited using another method. These results are shown in Table 8 and support Hypothesis $2\left(\mathrm{H}_{2}\right)$ : "Students are most likely to visit YouTube from a mobile device". Additionally, these results are consistent with the findings reported by Noel-Levitz (2012). Further, the accessibility of YouTube content by students via mobile devices may have implications for instructors, whose students may have inconsistent computer access or lack the software to properly access or view more traditional forms of content.

Table 8: Device Used To Access YouTube.

\begin{tabular}{|l|c|}
\hline Answer Options & Response Percent \\
\hline Phone or other Mobile Device & $57.5 \%$ \\
\hline Laptop or PC & $40.6 \%$ \\
\hline Other (game system, TV, etcetera) & $1.8 \%$ \\
\hline
\end{tabular}

\section{Hypothesis $3\left(\mathrm{H}_{3}\right)$ : Frequent users of social networking services like Facebook and YouTube are more likely to accept use of YouTube in the teaching and learning process}

In order to test Hypothesis 3 , two ANOVAs were conducted. The purpose of the ANOVAs was to examine whether there was a relationship between the frequency of the participant's personal use of YouTube and Facebook and their perceptions of the value of the use of YouTube in the teaching and learning process. During the interpretation of the ANOVAs, a significance level of less than 0.05 was deemed significant as it would result in the rejection of the null hypothesis at the 5\% significance level. Examining the $P$-values produced by the ANOVAs showed a lack of significance with all $P$-values greater than .0 .05 . These findings reject Hypothesis $3\left(\mathrm{H}_{3}\right)$ : "Frequent users of social networking services [SNS] like Facebook and YouTube are more likely to accept use of YouTube in the teaching and learning process" and are inconsistent with the research literature that has reported that there is a direct relationship between frequency of SNS use and student perceptions of the impact on the teaching and learning process (Cruse, 2013). Table 9 depicts the results of the ANOVAs.

Table 9: ANOVA Based on Social Networking Site Usage

ANOVA: Frequency of Use of YouTube and YouTube Can Enhance the Learning Process

\begin{tabular}{|l|l|l|l|l|l|}
\hline & SS & Df & MS & F & P \\
\hline Between: & 0.359 & 1 & 0.359 & 0.438 & $\mathbf{0 . 5 0 7}$ \\
\hline Within: & 360.894 & 440 & 0.820 & & \\
\hline Total: & 361.253 & \multicolumn{4}{|l|}{} \\
\hline ANOVA: Frequency of Use of Facebook and YouTube Can Enhance the Learning Process \\
\hline \multicolumn{7}{|l|}{} & SS & Df & MS & F & P \\
\hline Between: & 2.083 & 1 & 2.083 & 2.001 & 0.158 \\
\hline Within: & 458.053 & 440 & 1.041 & & \\
\hline Total: & 460.136 & 441 & & & \\
\hline
\end{tabular}




\section{Hypothesis $4\left(\mathrm{H}_{4}\right)$ : Length has an impact on the decision to view a video}

At one time YouTube had a length limit of 10 minutes. This limit was later changed to 15 minutes and then eliminated entirely in 2012, provided a user's account is in good standing. Since lifting the limit, there has emerged a tremendous range in the lengths of videos produced for higher educational use. As a result, one may surmise that length is often not a huge consideration in the video production process. Hypothesis 4 sought to explore whether video length is a line of inquiry worthy of detailed exploration. As a result, to examine the impact length has on viewing decisions, respondents were posed a dichotomous question. According to the responses $85.2 \%$ of participants affirmed that video length impacts their viewing decision with $7.4 \%$ in the negative and $7.4 \%$ unsure. These findings affirm Hypothesis $4\left(\mathrm{H}_{4}\right)$ : "Length has an impact on the decision to view a video" and are consistent with what has been reported by Greenberg and Zanetis (2012). The results are presented in Figure 4 and certainly indicate that length should play a factor in the video production and selection process by faculty.

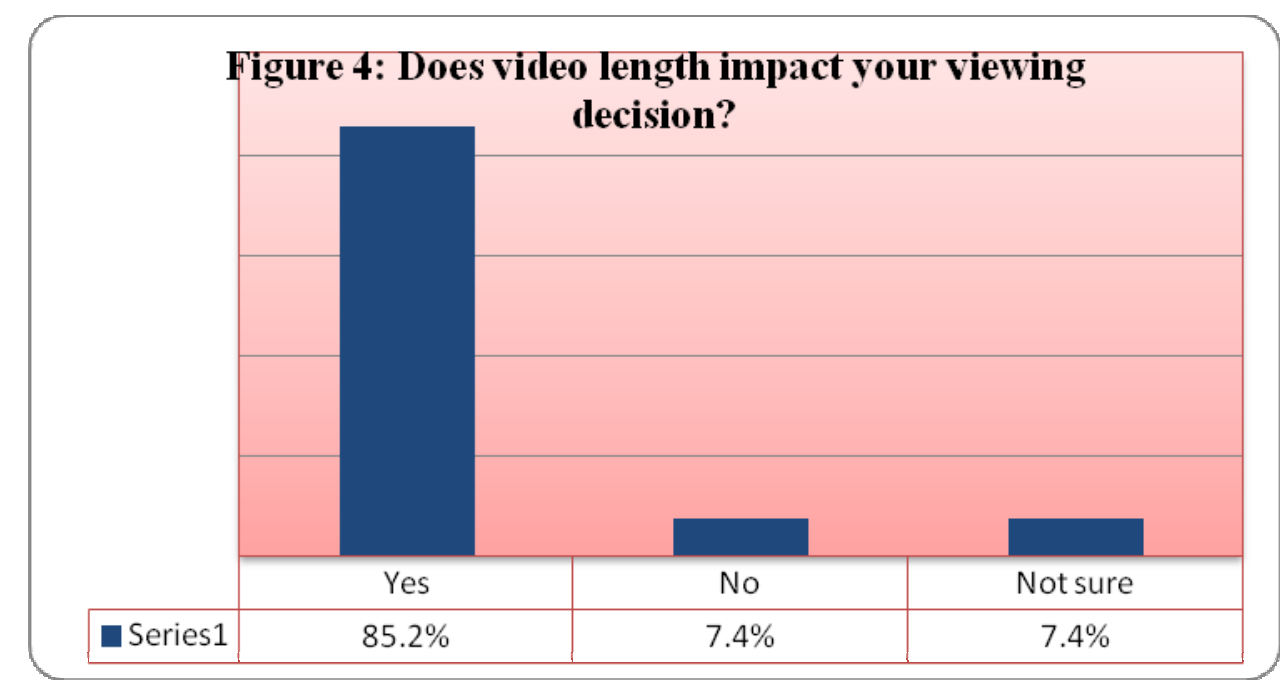

\section{Hypothesis $5\left(\mathrm{H}_{5}\right)$ : Course delivery format impacts length preferences}

Studies have shown that course delivery format impacts the perceptions of students with respect to the use of YouTube and other social networking services in the teaching and learning process (Buzzetto-More, 2013a; Jones \& Graham, 2013). This study sought to look specifically at ideal course video length, as well as whether course delivery format impacts perception of desired course video length. As a result, follow-up questions were posed to 100 students with a $71 \%$ response rate. These questions specifically referenced the instructor generated YouTube videos. Fifty-seven percent of respondents were enrolled in a fully-online section and $43 \%$ were enrolled in a hybrid section. In order to test Hypothesis 5, participants were asked to identify the ideal length for a course video. According to the findings, the in-person students indicated a preference for shorter videos at 1.5 to 3 minutes $(48.1 \%)$ while the online students indicated a preference for longer videos at 3-7 minutes in length (55.6\%). These findings take a more detailed approach than what was reported by Greenberg and Zanetis (2012) who found that shorter segments had greater appeal than longer segments recommending that videos refrain from exceeding 15 minutes in length. Additionally, the findings support Hypothesis $5\left(\mathrm{H}_{5}\right)$ : "Course delivery format impacts length preferences", something that has not been widely explored in the literature. The full results are represented in Figure 5 and hopefully, will inform college faculty about the importance of length consideration in the video production and selection process. 
Figure 5: Ideal Length for a Course Video

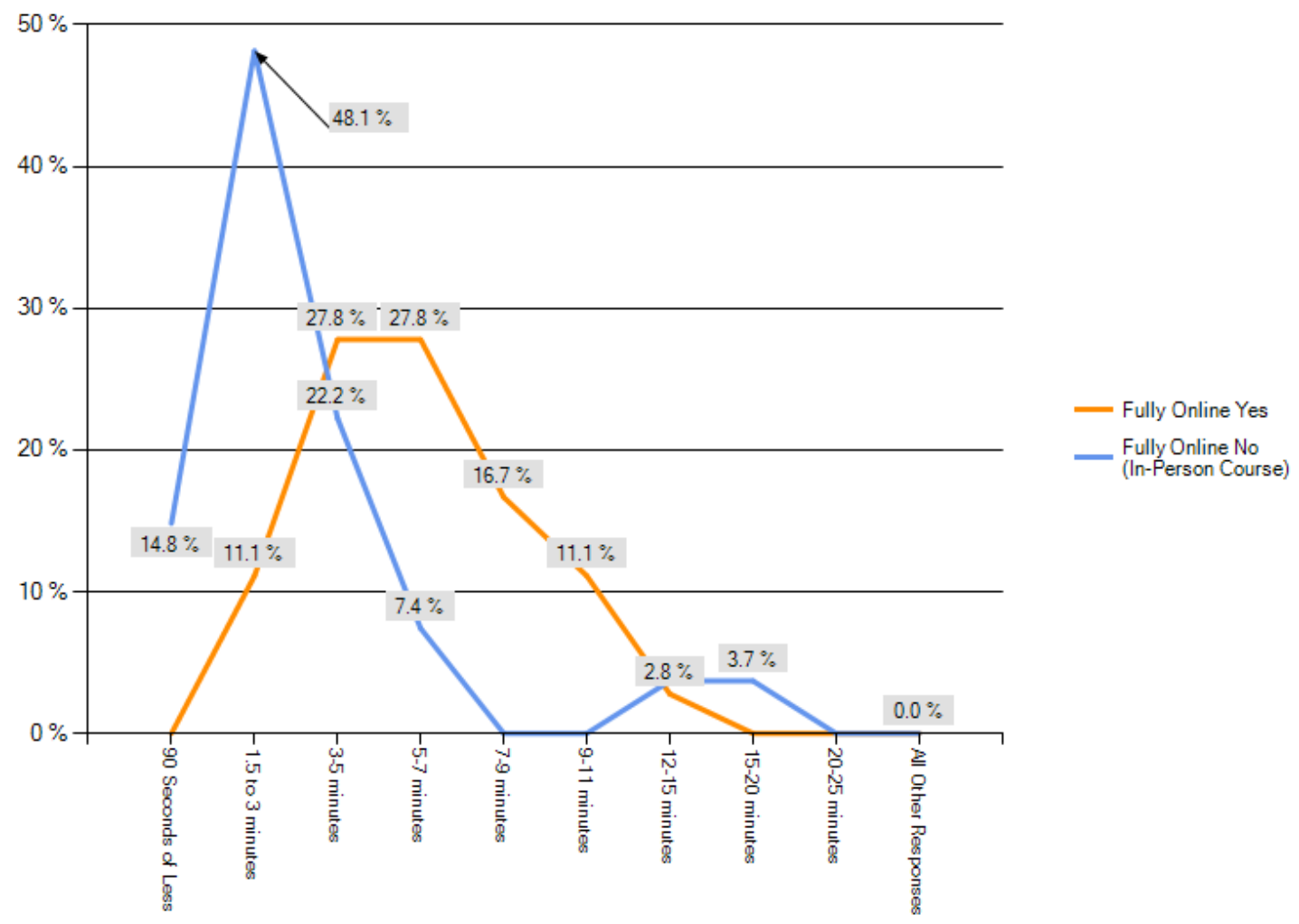

\section{Hypothesis $6\left(\mathrm{H}_{6}\right)$ : Course delivery format impacts audio preferences}

When an instructor produces or selects a video, he/she may or may not consider audio. During the follow up study, auditory preferences were explored with a special consideration to whether course delivery method impacted the audio preferences of students. These results were examined in order to test Hypothesis 6.

Information was gathered by asking the respondents to select between instructor narration, music, or other. According to the participants, $70 \%$ of online students selected instructor narration compared to $45 \%$ of hybrid students. Conversely, $64 \%$ of the hybrid students preferred music compared to $30 \%$ of fully online students. These results are consistent with what has been support Hypothesis $6\left(\mathrm{H}_{6}\right)$ : "Course delivery format impacts audio preferences." While this line of inquiry has not been previously explored with any significance in the literature, one may postulate that hybrid students preferred music over narration because they are regularly exposed to instructor delivered lectures; conversely fully online students preferred the greater personalization offered by instructor narration because they are not normally exposed to live lectures delivered by the instructor. The findings are presented in Table 10 and demonstrate that where audio is considered it is not a one size fits all model.

\begin{tabular}{|l|l|l|}
\hline \multicolumn{2}{|c|}{ Table 10: Auditory Preferences and Course Delivery Method } \\
\hline & Fully Online & Hybrid \\
\hline Instructor Narration & $70 \%$ & $45 \%$ \\
\hline Music & $30 \%$ & $64 \%$ \\
\hline Other & $0 \%$ & $1 \%$ \\
\hline
\end{tabular}




\section{Limitations}

The most significant limitation of this study is that it focused solely on business students attending a single small-sized U.S. public minority-serving university. In order to remedy the shortfalls inherent in this research, the researcher is looking to replicate this study at additional institutions of higher education.

\section{Conclusions}

The study presented in the current paper examined student perceptions with respect to the value and usefulness of YouTube as a pedagogical tool, finding that incorporation of YouTube enhances instruction and increases student interest. Online students especially indicated a greater preference for the adoption of YouTube than their hybrid and in-person counterparts.

Participating, students were found to be most likely to visit YouTube from a mobile device. The accessibility of YouTube content by students via mobile devices is significant in that it has implications to instructors whose students may have inconsistent computer access or lack the software to properly access or view other forms of content.

Frequency of use of social media was not shown to have an impact on student perceptions of the value of the use of YouTube in the teaching and learning process. Fully online students, however, exhibited greater voracity with respect to the perceived value added by the use of video sharing services than hybrid and classroom-based students.

Participants reported that video length impacts their viewing decision, indicating that length should play a factor in the video production and selection process by faculty. Further, fully online students indicated a preference for longer videos than their hybrid/in-person counterparts.

Auditory preferences were explored with a special consideration to whether course delivery method impacted the audio preferences of students. According to the findings, audio preferences varied across groups, with fully online students indicating a predilection for instructor narration, while hybrid/in-person students gave preferentiality to music.

In short, YouTube has tremendous potential to augment a wide-range of aspects of instruction, much of which has yet to be fully explored. It is the goal of this paper to encourage educators, especially those who teach in fully online learning environments, to embrace the use of video sharing services. Differences in perceptions based on course delivery method were explored as well as were certain design considerations. More detailed investigation into different possible video design specifications is needed such as captioning, alternating music and narration, different stylistic elements, framing, incorporation of speakers or panels, movement, lighting, transitions, additional audio options, the inclusion of actions to encourage prediction through such elements as implicit questioning. Further exploration into effective methodological approaches to including video should also be encouraged.

\section{References}

Berk, R. A. (2009). Multimedia teaching with video clips: TV, movies, YouTube, and mtvU in the college classroom. International Journal of Technology in Teaching and Learning, 5(1), 1-21.

Burke, S., \& Snyder, S. (2008). YouTube: An innovative learning resource for college health education courses. International Electronic Journal of Health Education, 11, 39-46.

Buzzetto-More, N. (2012a). Understanding social media. In C. Cheal, J. Coughlin, \& S. Moore (Eds.), Transformation in teaching: Social media strategies in higher education (pp. 1-18.). Santa Rosa, CA: Informing Science Press. 
Buzzetto-More, N. (2012b). Elevating social networking for a new age of edification. 18th Annual SLOAN Consortium International Conference on Online Learning. October 10-12, 2012. Orlando, Florida.

Buzzetto-More, N. (2012c). Social networking in undergraduate education. Interdisciplinary Journal of Information, Knowledge, and Management, 7, 63-90. Retrieved from http://www.ijikm.org/Volume7/IJIKMv7p063-090Buzzetto611.pdf

Buzzetto-More, N. (2013a). The use of YouTube to engage digital natives: Student preferences and perceptions in online and hybrid courses. Proceedings of the 19th Annual SLOAN Consortium International Conference on Online Learning. November 20-22, 2013. Orlando, Florida.

Buzzetto-More, N. (2013b). Social media and prosumerism. Issues in Informing Science and Information Technology, 10, 67-80. Available at http://iisit.org/Vol10/IISITv10p067-080Buzzetto0040.pdf

Cardine, S. (2008). Is education ready for YouTube? Center for Digital Education/Converge. Retrieved 9/10/13 from http://www.centerdigitaled.com/edtech/Is-Education-Ready-For-YouTube.html

Cruse, S. (2013). Using educational video in the classroom: Theory, research, and practice. Retrieved 9/12/2013 from http://www.safarimontage.com/pdfs/training/UsingEducationalVideoInTheClassroom.pdf

Duvenger, P., \& Steffes, E. (2012). Using YouTube videos as a primer to affect academic content retention. Working Together Works: Partnering for Progress 2012 CUMU National Conference. 23(2): 51-66.

Eick, C. J., \& King, D. T., Jr. (2012). Nonscience majors' perceptions on the use of YouTube video to support learning in an integrated science lecture. Journal of College Science Teaching. 42(1), 26-30.

eMBA. (2014). Top 15 most popular video viewing sites: February 2014. Retrieved 2/17/14 from http://www.ebizmba.com/articles/video-websites

Greenberg, A., \& Zanetis, J. (2012). The impact of broadcast and streaming video in education. Report Commissioned by Cisco Systems Inc. to Wainhouse Research L.L.C. Retrieved 2/10/14 from: http://www.cisco.com/web/strategy/docs/education/ciscovideowp.pdf

Hilner, J. (2012). How to use online video in your classroom. How teachers can bring the best of YouTube and other online video services to their students. Edutopia. Retrieved from: http://www.edutopia.org/youtube-educational-videos-classroom

Jaffar, A. A. (2012). YouTube: An emerging tool in anatomy education. Anatomical Sciences Education, $5(3), 158-164$.

Jones, N. B., \& Graham, C. (2013). Practices and tools in online course delivery. In Y. Kats (Ed.), Learning management systems and instructional design: Metrics, standards, and applications (pp. 288-302). Hershey, PA: Information Science Reference.

Liu, Y. (2010). Social media tools as a learning resource. Journal of Educational Technology Development and Exchange, 3(1), 101-114.

Logan, R. (2012). Using YouTube in perioperative nursing education. AORN, 95(4), 474-481.

Miller, M. (2009). Integrating online multimedia into college course and classroom: With application to the social sciences. MERLOT Journal of Online Learning and Teaching, 5(2), 395-423.

Noel-Levitz. (2012). the mobile browsing behaviors and expectations of college-bound high school students. E-Expectations Reports. Retrieved 11/3/2013 from: https://www.noellevitz.com/documents/shared/Papers_and_Research/2012/2012MobileExpectations.p $\underline{\mathrm{df}}$

Pratt, D., \& Feikes, D. (2013). Using online videos with preservice teachers to understand how children learn mathematics. Proceedings of the 24th Annual Society for Information Technology in Teacher Education Conference. March 25-29, 2013. New Orleans, LA.

Preece, J. (2014). Video share websites review. Top ten reviews. Retrieved 2/17/2014 from http://videoshare-review.toptenreviews.com/ 
Prigg, C. (2012). 100 more social media statistics for 2012. Retrieved 2/17/2014 from http://thesocialskinny.com/100-more-social-media-statistics-for-2012/

Sysomos. (2009). A look inside online video engagement. Retrieved 2/17/2014 from http://www.sysomos.com/reports/video/

Tan, E., \& Pearce, N. (2012) Open education videos in the classroom: Exploring the opportunities and barriers to the use of YouTube in teaching introductory sociology. Research in Learning Technology, 19, 128-137.

\section{Biography}

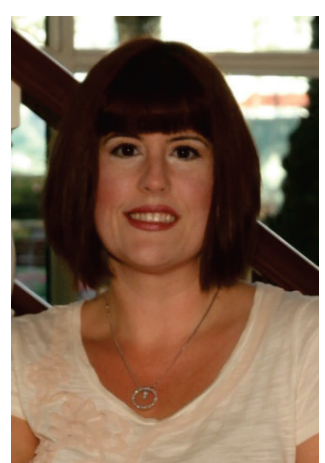

Dr. Nicole A. Buzzetto-More is an Associate Professor, Program

Coordinator, and the Assurance of Learning and Assessment Chair in the Department of Business at the University of Maryland Eastern Shore. She is also Director of the Maryland State Department of Education Program Affiliate for Business, Management, and Finance. She received doctorate and masters degrees from Columbia University and earned a post doctorate from Tulane University. She also earned a masters degree from the College of New Rochelle and a bachelor's degree from Marist College. Dr. Buzzetto-More is a frequent invited presenter at conferences across the globe; is on the editorial board of several journals; has authored numerous publications; and has been recognized with awards from the American Distance Education Consortium, Global Digital Business Association, and the Informing Science Institute. Recently, she was named a Fellow of the Informing Science Institute. She published two books in 2007, Principles of Effective Online Teaching and Advanced Principles of Effective ELearning. In 2010 her third book The E-Portfolio Paradigm: Informing, Educating, Assessing, and Managing with E-Portfolios was published by the Informing Science. She has also published a number of chapters in edited volumes, including a 2012 contribution to the book Transformation in Teaching: Social Media Strategies in Higher Education edited by Cathy Cheal. 